\title{
A qualitative study on barriers for the use of respiratory protective devices among rice mill workers in Ampara District, Sri Lanka
}

\author{
KRM Chandrathilaka ${ }^{1 *}$, Dulani Samaranayake ${ }^{2}$, Kantha Nirmali Lankatilake ${ }^{2}$, Rohini de Alwis \\ Seneviratne $^{3}$, Anuruddha Kumara Karunarathna ${ }^{4}$ \\ ${ }^{1}$ Department of Allied Health Sciences, Faculty of Medicine, University of Colombo, Sri Lanka; ${ }^{2}$ Department \\ of Community Medicine, Faculty of Medicine, University of Colombo, Sri Lanka; ${ }^{3}$ Faculty of Medicine, \\ General Sir John Kotelawala Defence University, Sri Lanka; ${ }^{4}$ Faculty of Agriculture, University of Peradeniya, \\ Sri Lanka
}

"Correspondence: chandrathilaka86521@gmail.com

https://orcid.org/0000-0001-9349-1491

DOI: https://doi.org/10.4038/jccpsl.v25i3.8198

Received on 26 February 2019

Accepted on 29 July 2019

\begin{abstract}
Introduction: Rice milling often carried out in the informal work sector generates paddy dust which is a hazard to the respiratory health of mill workers. Sri Lankan rice mill workers have shown reluctance in using respiratory protective apparatus during rice milling.
\end{abstract}

Objectives: To describe the barriers for the use of respiratory protective devices during rice milling

Methods: A qualitative study was conducted in the divisions of Ampara and Uhana in Ampara District in Sri Lanka during February 2016. Twenty-two in-depth interviews were conducted among rice mill workers, health professionals and government officers related to rice milling industry. Data were analysed using content analysis method.

Results: The rice mill workers' non-use of respiratory protective methods was mainly due to their negligence in personal respiratory health care and lack of support from the employer, health care institutes and other related institutes. Low level of comprehension of workers and less manpower in health care and other institutions were other contributing factors.

Conclusions: Low priority given for respiratory health care by the workers, poor work environment and less support from the mill owner and relevant government authorities have resulted in non-use of respiratory protective devices among rice mill workers. Improving unhealthy work behaviour such as non-use of respiratory protective devices of the informal work sector is recommended using industry-based health education programs.

Key words: informal workers, occupational health and safety, respiratory health, rice milling, work behaviour 


\section{Introduction}

Rice milling, which converts paddy grain to consumable rice is a dusty process (1) subjecting the workers to various respiratory health problems due to exposure to dust (2-3). Dust is a major occupational respiratory health hazard causing inflammatory reactions in the respiratory tract (4).

According to World Health Organization (WHO), workers' health can be affected by individual, enterprise and social factors (5). Studies have also shown that organisational structure, work pattern and peer influence directly affect the workers' protective behaviours in the workplace. Perceived severity of diseases, ability to pay for health facilities and ignorance on safe work procedures by the employees, pressure from the employer for higher work demands and unfriendly work environment (6-9) were among the key findings which have affected protective health behaviours.

Results from our baseline study (unpublished) showed that the rice mill workers were not using respiratory protective methods during rice milling activities. Thus, this study was aimed at describing the barriers affecting the use of respiratory protective devices among rice mill workers.

\section{Methods}

A qualitative study was conducted in February 2016 in Ampara and Uhana Divisional Secretariat Divisions of Ampara District, Sri Lanka.

In-depth interviews were used as the study instrument. A total of 22 interviews was conducted among conveniently selected rice mill workers, grass root level government administrative officers (Grama Niladhari/ GN) and public health staff including the medical officers of health $(\mathrm{MOH})$ and public health inspectors (PHI), district factory inspecting engineer and an agricultural officer of Post-harvest Technology Institute in Ampara. A preliminary survey conducted prior to this study revealed that most of the rice mill workers were males, therefore the mill workers selected for the study were males between the ages of 18-65 years. Having a minimum of three-year work duration was an inclusion criterion in their selection as they needed to have sufficient exposure in the work setting to be able to describe their perceptions on the use of respiratory protective devices. The maximum representativeness of workers was ensured by purposively recruiting only one worker from a rice mill, thus 12 workers from 12 rice mills out of 153 mills located in the study area.

Table 1. Summary of the in-depth interviews carried out with each occupational group

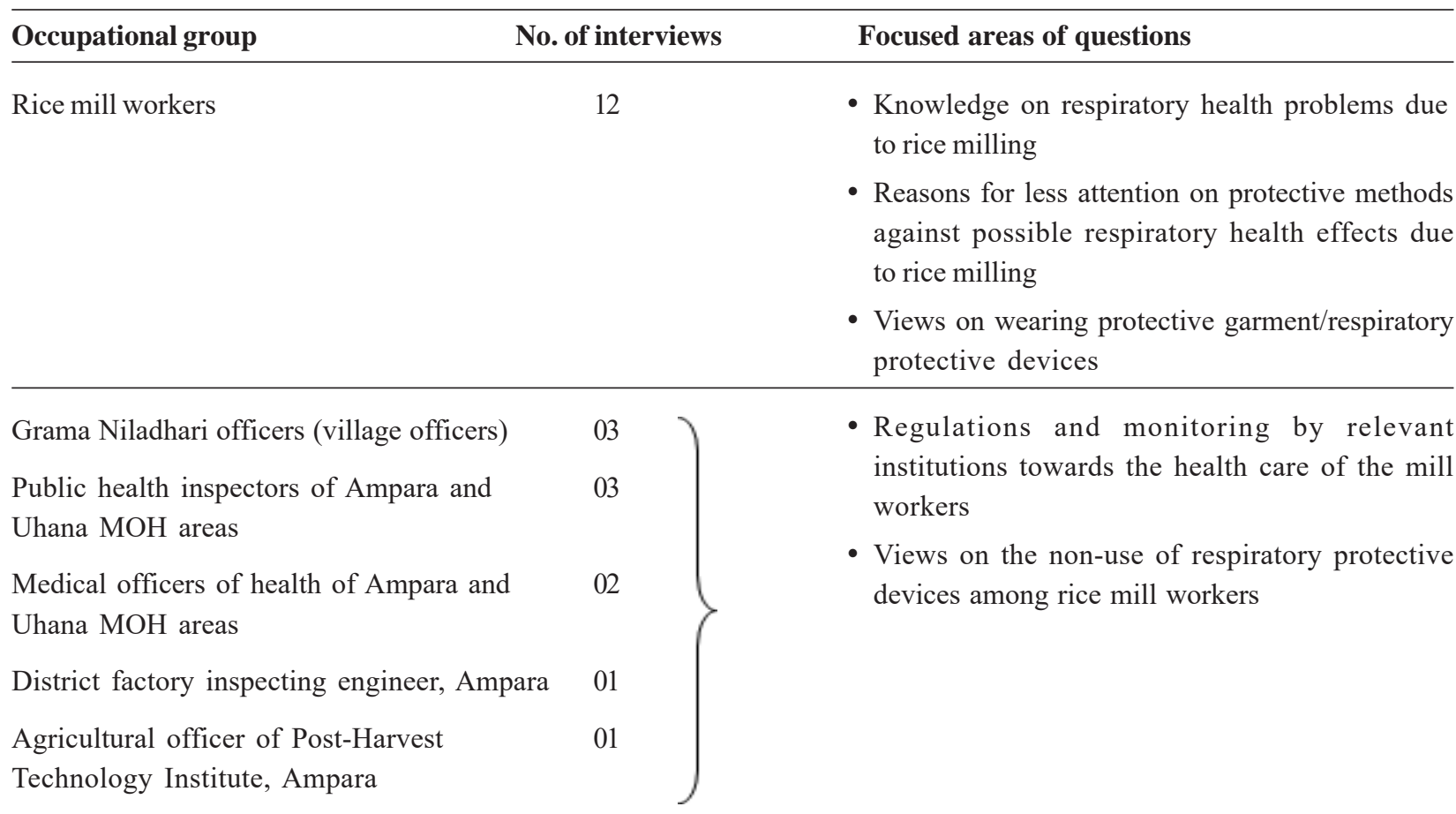


Table 1 shows the number of in-depth interviews conducted and the main themes focused upon for each occupational group. This number was deemed sufficient when additional interviews yielded little or no new information on the questions. Data were collected by the principal investigator having undergone training in qualitative methods prior to data collection. The interviews were conducted in the local language, Sinhala, after obtaining informed written consent from all the participants. The dialogues were audio recorded with prior permission from the participants and constantly checked to ensure uninterrupted recording. Notes were taken on key points raised during the interviews while keeping records on non-verbal communications, such as gestures, body movements and modulation of voice. Data were reviewed after each interview to assess how the questions were being answered before the next interview. All the audio recordings were transcribed, translated into English and back translated into Sinhala by a language expert. The translated documents were compared with the original Sinhala recordings to ensure that the same meaning has been retained. The data were analysed using content analysis method and key points were identified and coded to identify the factors affecting the studied behaviour among rice mill workers.

\section{Results}

The themes which were concluded as barriers for the use of respiratory protective methods by the rice mill workers are presented below.

\section{Attitudes and practices of rice mill workers towards their personal health}

All the participants were aware that rice dust causes respiratory health problems and thought it can be easily managed. Wheezing was recognized as a common health problem by most of the workers while three workers emphasized asthma as a common disease. One 53-year-old worker stated:

'The large amount of dust will be a problem to us and years of exposure to it may be harmful too.'

Further to their limited knowledge on health effects, most of the workers considered wheezing or cold as easily managed health conditions, which proved that they had given less priority to their respiratory health problems. A 48-year-old worker said:
'Often I get a watery discharge from my nose but don't go to the hospital because I manage it easily by drinking 'kasaya' (local traditional medicine) available at any shop. If it gets worse only, I go to a doctor.'

Reluctance and difficulty in attending health care facilities by the workers were also noted. Major reasons were fear of losing both the daily wage and the job due to being absent from work and irregular work patterns. One worker aged 40 years said:

'If we think about our health and take a rest, no one is there to think how my family is going to eat tomorrow.'

Another aged 46 years stated:

'We can' $t$ think of getting medicine for our diseases. If we don' $t$ go to work for a few days due to some reason, we would be replaced by another worker by the owner.'

A 45-year-old worker mentioned:

'Visit to the government hospital cannot be done regularly during our working time because we can't adjust our working time due to irregular working days in the mill.'

A cloth covering the mouth and nose and disposable masks were among the protective methods used against the dust by the workers. One 55-yearold worker mentioned:

'Most of us rarely wear at least a piece of cloth covering the nose and mouth during our work to prevent the dust. Some people use disposable masks which are available at low cost.'

However, they have rarely used those methods due to the difficulties such as feel of breathlessness and development of sweat specially around mouth and nose. A 42-year-old worker said:

'You can't imagine how difficult it is to wear a piece of cloth covering your face and work inside the mill... After five, ten minutes, I start to sweat under the piece of cloth and feel tired.'

Interestingly, most of the workers expressed their interest in wearing respiratory protective devices when they were informed about those. However, two of them termed it as a 'foolish idea'. A 45 and 53-year-old workers respectively mentioned: 
'I have to see whether it fits me. I have no idea how it would be'

'It may be irritating but like to wear it and test it.'

Thus, the mill workers have given low priority to their respiratory health problems due to economical disadvantages caused by being absent from work and difficulties in finding a suitable time to attend health care facilities. However, their proposed intention to use standard respiratory protective methods was positive.

\section{Employer support}

The mill owner has not considered the workers' health issues despite paying an insufficient health allowance occasionally. Thus, the workers have refrained from communicating their health problems to the owner. A worker aged 39 years stated:

'The owner of the rice mill where I work doesn't care about our health so that we rarely tell them about our health problems. He is only concerned in counting the number of rice bags we produce at the end of the day. Sometimes he gives money for medicine, however, this money is not enough because we normally attend private clinics.'

Further, negligence of installing dust and heat controlling methods by the owner was also raised by the workers. A 42-year-old worker said:

'There is no way of getting the heat out from the mill. There are pumps to send the husk and dust outside, however, those can't control all the dust accumulating inside the mill. The mill owner doesn't take these things seriously.'

Thus, lack of attention to health issues of mill workers and lack of improvements in milling environment by the mill owners have compelled the workers to continue working in an unhealthy work environment.

\section{Work environment}

According to the workers, major reason for not adhering to respiratory protective methods during work was the usual hot environment inside the mills. A worker aged 56 years stated:

'It is not that easy to wear even a sarong (a cloth wrapped around the waist to cover the lower part of the body) inside a building under this hot sun...I used a mask recently and was exhausted after few minutes with difficulty in breathing.'

Both the mill owners and the workers were reluctant in maintaining a clean environment inside the mills, despite the advice given by the public health staff, which has made the workers to continue with their unhealthy practices. One MOH said:

'We tell the mill owners on what they should do to maintain cleanliness in formal and informal ways. However, it seems that they don't follow our advice.'

Another PHI mentioned:

'Mill workers don't care about our guidance although we advise them regarding maintaining cleanliness inside the mills and its importance on workers' health.'

In the absence of necessary work environmental modifications for dust and heat control, difficulty in using respiratory protective methods under the prevailing hot climate was a major barrier for respiratory protection of the workers.

\section{Attitudes and practices of the government officers towards rice mill workers}

The workers' low level of comprehension was raised as the major reason for their non-adherence to advice on healthy work practices by all the interviewed government officers. One PHI mentioned:

'They find it difficult to understand what we say on their health because their level of education is low. Therefore, regular monitoring and reminders are essential to reinforce our educational messages.'

However, it was not clear whether the public health staff has addressed the rice mill workers' issues according to their level of understanding, as a 48-yearold worker said:

'I know dust creates problems, but there is nobody to educate me on what happens when the dust is inhaled and what I should do to work long in my job.'

\section{Institutional support}

Lack of health educational programmes conducted by the public health staff has led the rice 
mill workers to be unaware of health issues specific to them. The major reason raised by the staff was their busy schedule although occupational health and safety is a major component of their duty. One $\mathrm{MOH}$ said:

'It's in our duty list to conduct health education, however our work schedule is really heavy, and we don't have much staff to conduct them regularly.'

The workers received medical advice occasionally on their work practices. One worker was told to avoid dust exposure during his work by the medical officer only when he went for treatment for asthma, therefore availability of continuing guidance may force the workers towards protective work behaviour.

The health issues of workers were reported to the higher authorities by GN officers although the workers' behaviour was unchanged despite their interventions. One GN officer said:

'We often tell about workers' health and other issues to the higher administrative staff, but their suggestions have not made any change in the working pattern or in the milling environment. The reason mostly is these suggestions are not practical.'

The post-harvest technology officer suggested that the workers would have benefited if sufficient resources and staff were available.

'I can really contribute to educating the workers and mill owners on their health issues because I'm much familiar with these conditions. However, there are only few of us to carry on our duties.'

Further, the district factory inspecting engineer has not performed regular workplace monitoring in recent times due to the mostly spoken reason being, lack of support staff.

'I've not been to those mills recently and don't know the actual situation because no one is here to assist me to monitor the rice mills.'

Thus, despite occasional guidance on health protection, the absence of occupational health care services to address health problems specific to rice mill workers was highlighted.

\section{Discussion}

In the current study, we were able to describe the reasons which have discouraged the rice mill workers from practising respiratory protective devices (Box 1). Wheezing and asthma being the only known health effects of dust exposure according to the workers, these are assumed to be cured easily. This lack of knowledge on other long-term health effects such as fibrotic lung diseases, chronic bronchitis and pneumoconiosis (1-3) seemed to be a reason which has prevented them from practising protective methods. Demographic characteristics such as age, income and educational level have been reported as determinants of preventive behaviours of workplace injuries and accidents (10). These, as emphasized by the public staff in this study may also have affected the workers for their low comprehension about risks of dust exposure.

The mean respiratory and total dust levels inside the rice mills in this study area were higher than the respective threshold levels (11) as the mills were not regularly cleaned and they lacked dust extraction methods. Thus, the workers may have got used to this unsafe dusty work environment without following protective methods against dust exposure. Physically comfortable work environment (12), which has been considered as a factor related to workers' protective behaviour may have further enhanced the mill workers' behaviour even though they have experienced physical discomforts such as breathing difficulties.

Research studies have shown that perceived occupational risk level, being affected by working experience (8) and participation in occupational safety programs $(9,13)$, has had a major impact on health behaviour. In the current study, workers had never had opportunities to participate in health education programs, partly due to lack of attention from understaffed healthcare institutions and low importance given by government officers. This has lessened their attention towards personal health problems and understanding about the risks of dust exposure. Further, poor health seeking behaviour has led the workers to self-medication (14-15). This may be due to the cavalier attitude of the workers (7) towards their health issues as well as the preventive measures which demand the need for regular monitoring. 


\section{Box 1. Reasons for non-use of respiratory protective methods among rice mill workers}

\section{Attitudes and practices of RMWs towards their personal health}

- Limited knowledge on possible health effects of dust exposure

- Low priority given to respiratory health problems

- Reluctance and difficulties in attending health institutions

\section{Work environment factors}

- Perceived difficulty in working in hot climate by RMWs

- Insufficient control measures for dust and heat inside the mills

- Adhering to dirty work environment inside the mills due to lack of regular cleaning

\section{Employer factors}

- Lack of attention towards health needs of the workers by the mill owner

- Lack of communication between the workers and the mill owner

- Attitudes and practices of the government officers towards rice mill workers

- Negative perception of comprehension level of the RMWs regarding health problems

\section{Institutional factors}

- Lack of health screening, monitoring and education programs

- Lack of resource people and support staff to conduct health programmes

- Lack of communication between RMW and officials from relevant institutions

- Lack of practical approaches towards improving workers' health by policy makers

Less priority given to the workers' health by the employer (7), pressure imposed on the workers due to irregular work schedules and unpredictable work demands on the workers during a working day (16-17), which have been proven in literature, were also seen among the rice mill workers under study. Further, literature has shown that employee's fear of losing the daily wage has been related to their reluctance to seek health care $(9,12)$, which was raised by the mill workers in this study too, as they were concerned of safeguarding their jobs. Thus, it can be predicted that rice mill workers missed opportunities to receive medical advice for their respiratory health problems due to the above factors which would have led to nonuse of respiratory protective devices.

Openness of the employers and relevant authorities towards the health of rice mill workers is essential to understand the true nature of the workers' attitudes and beliefs (18), which was not seen among the workers. They had rarely been able to communicate with the officials relevant to rice milling industry. Lack of trust in the employer/ supervisor has been identified as a cause for information filtering by the employees when they convey their information upwards (19). Thus, the rice mill workers' fear of communicating their health matters to the mill owners may be due to lack of trust and understanding with the owners, which may have indirectly prevented them from reaching health care facilities.

Lack of commitment (20) and leadership support (21) from the employer have been major influences for safe behaviour, which were also indirectly highlighted by the participants. This lack of support from the mill owners and lack of communication with the relevant authorities regarding health issues have created an environment, which gives little or no priority 
for health in the rice mills and indirectly leads the mill workers towards unhealthy work practices.

Wearing respiratory protective devices against dust has been effective in reducing respiratory symptoms related to farmers' lung (22) and occupational asthma (23-24). The mill workers had a positive attitude towards wearing respiratory protective devices, which encourages developing health educational programmes to improve their current behaviour.

According to the Factories Ordinance of Sri Lanka (25), all practicable measures should be taken to protect the persons employed against inhalation of the dust and to prevent its accumulation in any workroom while providing and maintaining exhaust appliances. Further, International Labour Organization (ILO) (26) recommends that national policies should aim to identify and minimize the causes of occupational diseases, dangerous occurrences and incidents in the work environment. However, the government officers in this study seemed to have not taken remedial action for the workers' unhealthy behaviour despite the existence of international guidelines (26) and country regulations (25).

Being anxious about the interview and reluctance in expressing their views due to fear of the employer were the major barriers observed during the interviews with participants. Inclusion of professionals from various institutions related to rice milling has enabled the authors to analyse the study findings in a broader context. Ideas of the rice mill owners would have made the study findings more versatile however, their refusal to participate was a major limitation.

\section{Conclusions \& Recommendations}

The rice mill workers' non-use of respiratory protective devices was mainly due to the low priority given to personal respiratory health care as well as lack of support from the employer, health care institutes and other related institutes. Low level of comprehension of workers and less manpower in health and other institutions have intensified the problem. A general need to adhere to the health and safety policies according to the work setting was observed. Industry-based occupational health and safety programs are needed to address the specific health behaviour based on the occupation. Further investigations on the factors affecting unhealthy behaviour of informal work sector are highly recommended to enhance the workers' quality of life.

\section{Public Health Implications}

- Continuous exposure to dust is one of the major risk factors for acquiring respiratory health problems. Thus, the unhealthy behaviour of non-use of respiratory protective devices among workers who are continuously exposed to dust, such as rice mill workers should be addressed seriously.

- Finding reasons for their unhealthy respiratory practices facilitates the planning of preventive measures by occupational health professionals.

- Research, education and training of the employers and workers on dust control and use of personal protective methods by institutions related to occupational health and safety are essential in maintaining equity of health care.

\section{Author Declarations}

Competing interests: The authors declare that they have no competing interests.

Ethics approval and consent to participate: The study was approved by the Institutional Ethics Committee of the Faculty of Medicine, University of Colombo, Sri Lanka (EC 15-079). Written permission was obtained from the District Secretary and Regional Director of Health Services of Ampara prior to the commencement of the study. Informed written consent was obtained from the participants.

Funding: Higher Education for Twenty First Century (HETC) project of the World Bank [Ref number: HETC/CMB/QIGW3/MED/TOR-08].

Acknowledgements: The funding body is gratefully acknowledged by the authors.

Author contributions: All the authors contributed in designing and analysing the results of the study. The first author collected the data and drafted the manuscript. All authors proofread and modified the article. 


\section{References}

1. Lim HH, Domala Z, Joginder S, Lee SH, Lim CS, Bakar CMA. Rice millers' syndrome: a preliminary report. British Journal of Industrial Medicine 1984; 41(4): 445-449.

2. Musa R, Naing L, Ahmad Z, Kamarul Y. Respiratory health of rice millers in Kelantan, Malaysia. Southeast Asian Journal of Tropical Medicine \& Public Health 2000; 31(3): 575-578.

3. Abeysekara NTQM. A study of the respiratory and other disorders in rice millers following exposure to dusts of occupational origin. MD Thesis. Colombo: University of Colombo, 1994.

4. Dewangan KN, Patil MR. Evaluation of dust exposure among the workers in agricultural industries in NorthEast India. Annals of Occupational Hygiene 2015; 59(9): 1091-1105.

5. WHO. Good practice in occupational health services: a contribution to workplace health. Copenhagen: WHO Regional Office for Europe, 2002.

6. Asampong E, Dwuma-Badu K, Stephens J, et al. Health seeking behaviours among electronic waste workers in Ghana. BMC Public Health. 2015; 15: 1065.

7. Brown KA, Willis PG, Prussia GE. Predicting safe employee behavior in the steel industry: development and test of a sociotechnical model. Journal of Operations Management 2000; 18(4): 445-465.

8. Kroeger A. Anthropological and socio-medical health care research in developing countries. Social Science \& Medicine 1983; 17(3): 147-161.

9. Keenan V, Kerr W, Sherman W. Psychological climate and accidents in an automotive plant. Journal of Applied Psychology 1951; 35(2): 108-111.

10. Oliver A, Cheyne A, Tomas JM, Cox S. The effects of organizational and individual factors on occupational accidents. Journal of Occupational and Organizational Psychology 2002; 75(4): 473-488.

11. Chandrathilaka KRM, Senevirathne SR De A, Lankatilake KN, Samaranayake DBDL, Karunarathna AK. Work environment of automated and nonautomated rice mills in Ampara district, Sri Lanka. International Journal of Community Medicine \& Public Health 2018; 5(8): 3257-3264.

12. Cheyne A, Cox S, Oliver A, Tomas JM. Modeling safety climate in the prediction of levels of safety activity. Work Stress 1998; 12(3): 255-271.

13. Goldberg AI, Dar-El EM, Rubin A-HE. Threat perception and the readiness to participate in safety programs. Journal of Organizational Behavior 1991; 12(2): 109-122.
14. Peng Y, Chang W, Zhou H, Hu H, Liang W. Factors associated with health-seeking behaviour among migrant workers in Beijing, China. BMC Health Services Research 2010; 10: 69.

15. Donkor ES, Tetteh-Quarcoo PB, Nartey P, Agyeman IO. Self-medication practices with antibiotics among tertiary level students in Accra, Ghana: a crosssectional study. International Journal of Environmental Research \& Public Health 2012; 9(10): 3519-3529.

16. Embrey DE. Incorporating management and organizational factors into probabilistic safety management. Reliability Engineering \& System Safety 1992; 38: 199208.

17. Wright C. Routine deaths: fatal accidents in the oil industry. The Sociological Review 1986; 34(2): 265 289.

18. Milliken FJ, Morrison EW, Hewlin PF. An exploratory study of employee silence: issues that employees don't communicate upward and why. Journal of Management Studies 2003; 40(6): 1453-1476.

19. Read W. Upward communication in industrial hierarchies. Human Relations 1962; 15(1): 3-15.

20. Hofmann DA \& StetzerA. A cross-level investigation of factors influencing unsafe behaviors and accidents. Personnel Psychology 1996; 49(2): 307-339.

21. Thompson RC, Hilton TF, Witt LA. Where the safety rubber meets the shop floor: a confirmatory model of management influence on workplace safety. Journal of Safety Research 1998; 29(1): 15-24.

22. Wening DM \& Repp H. Investigation on the protective value of breathing masks in farmer's lung using an inhalation provocation test. Chest 1989; 95(1): 100105.

23. Obase Y, Shimoda T, Mitsuta K, Matsuse H, Kohno S. Two patients with occupational asthma who returned to work with dust respirators. Occupational \& Environmental Medicine 2000; 57: 62-64.

24. Taivainen AI, Tukiainen HO, Terho EO, Husman KR. Powered dust respirator helmets in the prevention of occupational asthma among farmers. Scandinavian Journal of Work, Environment \& Health 1998; 24(6): 503-507.

25. International Labour Organization. Recording and notification of occupational accidents and disease. An ILO Code of Practice. Geneva: International Labour Office, 1996.

26. Department of Labour and Nationalised Services. Factories (No.1) Regulations. Government of Ceylon, 1961. 